\title{
Nem Só de Pão se Vive: A Voz das Mães na Obesidade Infantil ${ }^{1}$
}

One Does Not Live Of Bread Only: The Mothers' Voice In The Child's Obesity

No Solo De Pan Se Vive: La Voz De Las Madres En La Obesidad Infantil
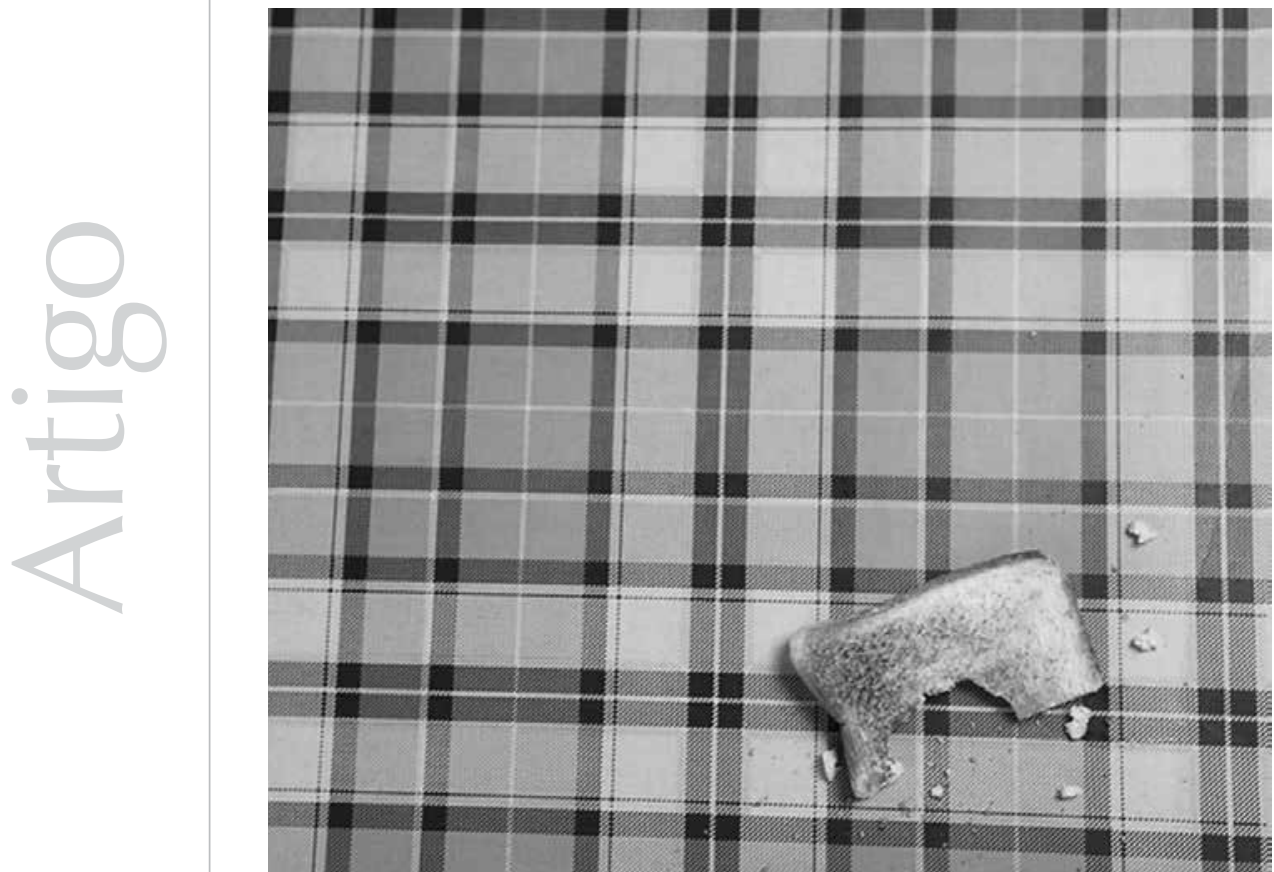
Resumo. A obesidade infantil tornou-se uma preocupação mundial e de saúde pública. Sabe-se que existem diversos fatores que predispõem à doença (biológicos, econômicos, pessoais, socioculturais e familiares), porém, nesta pesquisa, o objetivo geral foi compreender os elementos presentes na história familiar de crianças com obesidade. Participaram seis mães e uma avó de crianças, na faixa etária entre oito a dez anos incompletos, que se encontravam em atendimento em um ambulatório de referência para obesidade infantil. Foi utilizada uma entrevista com roteiro previamente estabelecido e, posteriormente, os resultados foram analisados com base na análise de conteúdo temática. Pode-se concluir que as famílias apresentaram falta de coesão acerca das normas alimentares e de limites à criança, conflitos conjugais e familiares e dificuldades em adequar o ambiente às recomendações solicitadas pelos profissionais.

Palavras-chave: Obesidade infantil. Controle de peso. Distúrbios do ato de comer. Relação familiar.

Abstract. Childhood obesity has become a global and a public health concern. Although we are aware that there are several factors that predispose to the disease (biological, economic, personal, social, cultural and familial), the general objective of this research was focused on understanding the elements present in children with a family history of obesity. The participants were six mothers and one grandmother of children aged between 8-10 years old, who were in attendance in an outpatient clinic of reference for childhood obesity in Recife. An interview with previously established routine was used, and later the results were analyzed based on the thematic content analysis. It can be concluded that the families showed lack of cohesion about the food standards and limits to the child, familial and conjugal conflicts, and difficulties in adapting the environment to the assistance requested by the professionals.

Keywords: Obesity in children. Body weight. Eating disorders. Family relations.

Resumen. La obesidad infantil se volvió una preocupación mundial y de salud pública. Se sabe que existen diversos factores que predisponen a la enfermedad (biológicos, económicos, personales, socioculturales y familiares), sin embargo, en esta investigación, el objetivo general fue comprender los elementos presentes en la historia familiar de niños con obesidad. Participaron seis madres y una abuela de niños, con edades entre ocho a diez años aún no completados, que se encontraban en servicio en una clínica de referencia para obesidad infantil. Fue utilizada una entrevista con un guión previamente establecido y, posteriormente, los resultados fueron analizados con base en el análisis del contenido temático. Se puede concluir que las familias presentaron falta de cohesión acerca de las normas alimenticias y de límites al niño, conflictos conyugales y familiares y dificultades en adecuar el ambiente a las recomendaciones solicitadas por los profesionales.

Palabras clave: Obesidad del niño. Peso del cuerpo. Transtornos de la ato de comer. Relación familiar.

${ }^{1}$ Esta pesquisa é parte da dissertação de mestrado intitulada:

Obesidade Infantil: Instalação e

Manutenção, na Perspectiva dos Pais, elaborada pela primeira autora, sob orientação

da segunda e apoiada através da concessão de bolsa pela Fundação de Amparo à Ciência e Tecnologia do Estado de Pernambuco

(FACEPE).
A obesidade é definida pela Organização Mundial de Saúde (OMS, 2006) como o acúmulo anormal ou excessivo de gordura que pode prejudicar a saúde. Provavelmente ela seja uma das enfermidades mais antigas do homem. As recomendações quanto à manutenção e aos cuidados em relação ao peso corporal já apareciam nos escritos de Hipócrates e Platão. À medida que os séculos foram passando, as migrações, a capacidade de organização humana e o fim do nomadismo determinaram mudanças na aparência corporal. A ocorrência de guerras, períodos de carência de alimentos e a fixação do homem no campo contribuíram para maior proporcionalidade nos modos de viver, de comer e do próprio corpo do homem (Setian, 2007).
A obesidade está se tornando um grande problema para as crianças e os adolescentes dos países ocidentais. O Brasil é considerado um país em transição nutricional, pela substituição da desnutrição - decorrente da escassez de alimentos - pela obesidade, devido ao excesso e à inadequação do consumo alimentar. O Instituto Brasileiro de Geografia e Estatística (IBGE, 2010), através da Pesquisa de Orçamentos Familiares (POF) referente aos anos 2008-2009, divulgou que o peso dos brasileiros, nos últimos anos, vem aumentando, o que tem como resultado a diminuição da desnutrição e o aumento da obesidade em crianças. O excesso de peso e a obesidade têm sido encontrados com frequência a partir dos cinco anos de idade, em todos os grupos de renda e regiões 
brasileiras (IBGE, 2010; Simon, Souza, Leone, \& Buongermino de Souza, 2009).

A etiologia da obesidade é considerada multifatorial por envolver fatores orgânicos, ambientais, comportamentais, psicossociais e socioeconômicos, o que a torna, assim, bastante complexa; é um fator de risco à saúde, e pesquisas têm sido sugeridas no intuito de combater os fatores envolvidos na sua origem e manutenção. Ela é definida como o anormal ou excessivo acúmulo de gordura, como uma doença, uma síndrome, um aspecto do nosso metabolismo ou a falta de controle sobre o ato de comer (Fisberg, 2004; OMS, 2006).

Neste estudo, adotou-se o referencial teórico da teoria sistêmica, uma vez que esta caracteriza a família como um sistema composto por vários integrantes, ou subsistemas, que interatuam e se influenciam mutuamente. Compreende-se, assim, que a obesidade em um dos membros ocasiona mudanças no sistema familiar como um todo.

\section{Repercussões psíquicas da obesidade na infância}

É sabido que a alimentação ocupa papel importante na relação entre pais e filhos, pois, além de ser um modo de manter o indivíduo vivo e aplacar a fome, o ato de comer é um meio de troca de afeto, comunicação, interação e, por vezes, também de oposição. A família é responsável pela formação do comportamento alimentar da criança através de uma aprendizagem social, sendo os pais os primeiros educadores nutricionais. Dessa maneira, como outros ambientes socialmente influentes, o núcleo familiar interage com as predisposições genéticas e psicológicas à obesidade infantil (Spada, 2005; Murdoch et al., 2011).

A teoria sistêmica privilegia a compreensão dos indivíduos através do estudo das suas relações com o meio social e o familiar, entendendo a família como uma organização, a partir dos seguintes elementos: a) conexões entre as pessoas, b) padrões de funcionamento familiar, c) regras implícitas e explícitas que orientam as interações, bem como a natureza dos limites. De acordo com essa teoria, é possível identificar as habilidades e a eficácia de cada família para resolver os conflitos e para criar regras (Osorio, 2004; Aun, Vasconcellos, \& Coelho, 2005).

Pensando sobre o processo de formação da família, Houzel (2004) assinala que não basta ser genitor ou ser designado como pai/mãe para exercer a parentalidade. É necessário tornar-se pais, e isso acontece por um processo complexo que o autor chama de experiência de parentalidade. Ela se constitui pelo conhecimento subjetivo consciente e inconsciente do que implica ser pais e do desempenho dos papéis parentais. $\mathrm{O}$ autor destaca dois aspectos desse processo: a) o desejo pela criança, que foi objeto de numerosas hipóteses psicanalíticas e sistêmicas e, de acordo com a última, corresponde à noção de dívida de vida, que diz respeito ao fato de a mulher grávida tornar-se mãe e ocupar o lugar da sua mãe, ou seja, o que foi recebido deve ser transmitido para restaurar a homeostase ou equilíbrio familiar, b) o processo de parentificação, que é mais conhecido, sobretudo pelas mulheres, durante o desenvolvimento do feto/bebê. Esse processo pode ter início na gravidez quando surge, no psiquismo da mulher, uma nova organização para os investimentos na maternagem.

Autores como Wagner e Mosmann (2009) acreditam que as características da relação conjugal se expressem de forma direta na parentalidade e tenham consequências sobre o ajustamento dos filhos. Assim, por um lado, as relações conjugais com bons níveis de satisfação podem atuar como fonte de apoio para os cônjuges em relação à parentalidade. Por outro lado, casais com altos níveis de 
conflito conjugal podem ser inconsistentes, não responsivos, indiferentes e não afetivos, tornando-se inadequados ou incapazes de proteger e de monitorar os filhos.

Menendez et al. (2004) dizem que, para o homem, a passagem do status de genitor ao de pai pode ser considerada um ato de nascimento social. No entanto, é a representação que o homem faz de si mesmo como pai que o transformará e fará que a função paterna comece. Os autores acreditam que há capacidades de interação no pai que irão facilitar a paternagem, e uma delas seria a de embalar, descobrir a criança durante suas trocas afetivas, e essa flexibilidade facilitaria também a função materna, não no sentido de substituí-la, mas de complementá-la.

Para Missonnier (2004), outro componente importante no processo de tornar-se pais é a qualidade da presença dos avós, principalmente no que diz respeito à relação da jovem grávida com a própria mãe. As relações marcadas por conflitos - no período da chegada do bebê - acarretam uma vulnerabilidade desnecessária, visto que o momento é de receptividade para troca de informações e apoio, o que possibilitaria maior reaproximação entre elas. Afinal, os interesses da mulher grávida nesse momento são dirigidos para sua mãe como mãe, e menos para a mãe como mulher. Assim, ela pode sentir o desejo de amar e de cuidar de sua criança como ela teria desejado ser amada.

O aumento da expectativa de vida e as mudanças no contexto social e cultural delinearam diferentes atribuições para os avós nas últimas décadas. Saindo do papel tradicional de provedores de presentes e carinhos, eles passaram a ser mediadores dos conflitos entre os filhos e os netos, proporcionando muito afeto e pouca repreensão a estes últimos. Atualmente, com certa frequência, os avós desempenham o papel de pais com todas as funções pertinentes, seja pelo fato de ambos os pais trabalharem fora de casa e não terem com quem deixar a criança, seja pela convivência no mesmo lar (Dias, Aguiar, \& Hora, 2009).

Dessa forma, é no contexto de trocas afetivas e cuidados que se formará o vínculo entre a criança e quem cuida dela. Quando há acolhimento e segurança no ambiente, a criança desenvolve uma ligação forte que proporcionará uma base segura para explorar o mundo que a cerca, e quando houver dificuldades ou sentir-se ameaçada, ela poderá retornar a esse refúgio emocional seguro. Quando esse vínculo não se desenvolve de forma adequada, há um potencial para problemas emocionais (Bayer, Vasco, Lopes, \& Teixeira, 2010; Spada, 2005).

Bruch acredita que "os problemas emocionais e psicológicos podem afetar crianças obesas, no entanto, não há um perfil ou uma estrutura mental única para esses indivíduos, sendo arriscada a generalização dos problemas psicológicos para todos os casos de obesidade" (1977). Segundo a autora, é importante diferenciar as desordens psíquicas que desempenham papel importante no desenvolvimento da obesidade, daquelas que sobrevêm do estado obeso, principalmente vivendo-se em uma cultura hostil ao sobrepeso. Acredita-se ser delicada e difícil essa diferenciação devido aos vários fatores envolvidos na obesidade infantil. O mais evidente é que determinadas dificuldades psicológicas estão sempre presentes, e podem estar entre os fatores determinantes da obesidade exógena (decorrente de um desequilíbrio entre a ingestão e o gasto calórico) ou ser consequentes à obesidade endógena (proveniente de uma disfunção do organismo). 
A mesma autora considera que a obesidade acarreta prejuízo à vida social da criança, dificultando sua relação com os outros e seu desempenho em atividades compartilhadas, e salienta que a obesidade não possui a dignidade das outras doenças e nem sempre é levada a sério; assim sendo, muitas vezes ela pode ser encarada pelos adultos como cômica.

Os autores que trabalham com obesidade infantil são unânimes em afirmar que o estabelecimento de um vínculo conflituoso/ inseguro na infância poderá desencadear e atuar na manutenção da doença (Lemes, 2004; Mishima \& Barbieri, 2009; Coppins et al., 2011). Uma das explicações para isso seria a predisposição da criança para se tornar obesa. A outra poderia ser resultante de um comportamento compensatório dos pais, ou seja, diante da dificuldade para oferecer afeto ao filho, eles o substituem por alimento.

De acordo com Cataneo, Carvalho e Galindo (2005), algumas crianças obesas sofrem discriminação e estigmatização, o que prejudica seu desenvolvimento físico e psíquico, pois podem causar um impacto negativo em sua qualidade de vida e demarcar obstáculos para efetivar mudanças no comportamento alimentar. As crianças acometidas pela obesidade são frequentemente importunadas pelos colegas e menos aceitas do que as crianças com peso normal, sendo que, ao longo da vida, o excesso de peso traz outras dificuldades, como: mudanças de humor, menor índice de empregos, timidez, autoestima baixa (Luiz, Gorayeb, Liberatore Júnior, \& Domingos 2005; Luiz, Gorayeb, \& Liberatore Júnior, 2010).

Lemes complementa dizendo que, quando as crianças obesas sofrem discriminação, é muito comum vê-las se queixarem de algum mal-estar para não ir à escola, desistirem de participar de esportes para evitar expor o corpo, recusarem-se a ir a uma festa porque se acham diferentes e dizerem que nenhuma roupa fica boa. O sistema familiar também acentua o problema quando os pais, em um momento de raiva, podem usar um apelido pejorativo, o irmão magro pode agredir verbalmente a criança obesa com apelidos e piadas, os pais, na ânsia de terem um(a) filho(a) magro, podem acabar exigindo muito dele(a) e os avós podem tomar partido do(a) neto(a) obeso(a) e acreditarem que têm que comer mesmo.

No que se refere à autoestima, Bastos considera que a criança não nasce com autoestima baixa, pois esta se desenvolve durante sua vida e nas relações estabelecidas com os demais, a partir de modos de olhar significativos que recebe desde os primeiros anos, em interação com seu contexto social. Também é composta pelos sentimentos de "amor a si mesmo, visão de si mesmo e autoconfiança" 2005, (p.37), os quais possibilitam desenvolver recursos que proporcionam condições para seu êxito ou seu fracasso. O mesmo autor acrescentou que, entre os vários fatores envolvidos no desenvolvimento da autoestima, o mais relevante é o meio social onde a criança está inserida.

De tanto serem tratadas como diferentes, as crianças obesas começam de fato a se sentir assim. É como se elas não pertencessem a lugar nenhum, exceto quando encontram outra criança na mesma condição que a sua. Assim, começam a se sentir incapazes para fazer qualquer coisa, ficam desmotivadas e acham que não adianta tentar, afinal, elas não conseguirão mesmo. Quando a autoestima está muito baixa, elas começam a se achar insignificantes e, às vezes, acabam encontrando uma forma de se relacionar com os colegas, sendo as boazinhas do grupo e fazendo o que os demais não fazem para agradar-Ihes (Lemes, 2004). 
Outro aspecto bastante citado como presente no indivíduo obeso é a ansiedade. Andrade e Gorenstein (1998) afirmam que esse é um estado emocional que inclui componentes psicológicos e fisiológicos, e que ele faz parte do espectro normal das experiências humanas e é propulsor do desenvolvimento, mas que se torna patológico quando é desproporcional à situação que o desencadeia.

A depressão pode ser também sintoma de patologias orgânicas e desenvolver-se na criança obesa. Ela se manifesta através do apetite continuamente maior bem como de sentimentos de tristeza, irritabilidade, agressividade e fadiga crônica, apresentada como reclamações de cansaço, a depender da intensidade e da frequência. Tudo isso pode caracterizar sintomas depressivos e interferir na vida da criança, acarretando dificuldades comportamentais no seu relacionamento social (Baptista,Vargas, \& Baptista, 2008; Luiz et al., 2005).

Outra patologia muito comum em portadores de obesidade é o comportamento de comer compulsivamente, também conhecido como transtorno da compulsão alimentar periódica (TCAP). Ele foi descrito pela primeira vez na década de 50, por acometer indivíduos obesos que estavam em tratamento para emagrecer, e foi caracterizado por episódios recorrentes de descontrole alimentar, com ausência de comportamentos compensatórios inadequados (indução de vômitos ou ingestão de laxantes) para promover a perda ou para evitar o ganho de peso. Além da ingestão excessiva de alimentos, estados afetivos são descritos como aliados do comer compulsivo, como: tristeza, vergonha, culpa, além de acentuada angústia. Outra observação que se faz é o desenvolvimento dessa patologia associada a famílias que apresentam algum tipo de transtorno afetivo, de personalidade ou de dependência de substâncias (Costa et al., 2009; Pereira \& Chehter, 2011; Pisciolaro \& Azevedo, 2010; Edwards et al., 2006).

Esta pesquisa, portanto, teve como objetivo geral compreender os elementos presentes na história familiar das crianças com obesidade, e, especificamente, os sentimentos expressos pelas famílias frente ao problema, buscando o entendimento de possíveis fatores que predispõem e mantêm a obesidade na infância.

\section{Método}

\section{Participantes}

A pesquisa foi realizada em um ambulatório de referência em obesidade infantil na cidade do Recife-PE. Nesse ambulatório, atendemse crianças não somente da comunidade como também oriundas de outras localidades (interiores do Estado de PE e da BA). Participaram do estudo seis mães e uma avó, com idades entre 29 e 59 anos, de crianças de ambos os sexos, na faixa etária entre 8 a 10 anos incompletos. Os critérios de inclusão na pesquisa foram: as mães deveriam ter filhos que apresentassem índice de massa corporal (IMC) acima do percentil 95, os filhos serem diagnosticados com obesidade pelos nutricionistas do ambulatório, a causa do excesso de peso não se dever a distúrbios endocrinológicos e as crianças estarem na faixa etária entre 6 e 10 anos incompletos.

\section{Instrumento}

Utilizou-se uma entrevista com roteiro, que foi conduzida de forma semidirigida. O roteiro foi constituído pelos dados sociodemográficos das mães (nome, idade, sexo, escolaridade, número de filhos, situação empregatícia, local onde mora e estado civil), das crianças (nome, sexo, idade, escolaridade, estatura, 
peso, percentil corporal, IMC e com quem reside) e questões que procuraram atender os objetivos da pesquisa (condições da gravidez, hábitos alimentares da família e da criança, relacionamento da criança com pais, irmãos e colegas, relacionamento entre os pais, início da obesidade, e expectativa da família frente ao tratamento). Essas questões nortearam a análise dos dados.

\section{Cuidados éticos}

O projeto de pesquisa $\mathrm{n} \mathbf{0} 1646$ foi aprovado pelo Comitê de Ética da instituição que o apoiou. Antes de cada entrevista, foi apresentado e assinado pelas participantes $\mathrm{O}$ Termo de Consentimento Livre e Esclarecido, conforme a resolução no 196/96 do Conselho Nacional de Saúde (Brasil, 1996).

\section{Procedimentos de coleta dos dados}

O local para realização das entrevistas foi uma sala de atendimento cedida pelo ambulatório. As entrevistas foram realizadas individualmente, e tiveram duração de aproximadamente uma hora. Foram dados nomes fictícios para preservar a identidade dos participantes e utilizado um gravador, com a autorização das entrevistadas.

\section{Procedimentos de análise dos dados}

Os resultados foram transcritos e analisados de acordo com a técnica da análise de conteúdo temática, seguindo os passos adotados por Minayo (2007): pré-análise, exploração do material e interpretação dos resultados obtidos. A pré-análise consiste na primeira etapa em que há a organização do material a ser analisado. Nessa fase, foi realizada a leitura exaustiva dos relatos das entrevistadas, buscando as informações que pudessem responder aos objetivos da pesquisa. Na exploração do material, foi realizado um recorte em suas unidades de registro, identificando-se os temas que foram trabalhados. Por fim, na interpretação dos resultados, as observações das entrevistadas foram analisadas com base nos autores pesquisados.

\section{Resultados e discussão}

\section{Perfil sociodemográfico das crianças e das mães}

Inicialmente, o objetivo da pesquisa era entrevistar as mães e os pais das crianças em tratamento. No entanto, devido ao não comparecimento dos pais ao ambulatório, delineou-se a pesquisa para se entrevistar os responsáveis que acompanhavam a criança. Dessa maneira, foram entrevistadas seis mães e uma avó, assim caracterizadas: 1) Adriana possui segundo grau completo, é dona de casa, divorciada, e tem dois filhos (mãe de Jaime), 2) Lúcia possui ensino fundamental incompleto, é dona de casa, viúva, e tem duas filhas (mãe de Laura), 3) Lourdes cursou magistério, é professora, casada e tem um filho (mãe de Paulo), 4) Maria possui segundo grau completo, é vendedora de loja, casada, e tem um filho (mãe de Caio), 5) Marcela possui ensino fundamental incompleto, é manicure, solteira, e mãe de quatro filhos (mãe de Edna), 6) Marta possui ensino técnico de estética, é esteticista, divorciada, e tem um filho (mãe de Marcos) e 7) Jacira possui segundo grau completo, é aposentada, casada, tem três filhos, e apenas Joana de neta.

Das sete crianças, três (Jaime, Joana e Marcos) moram com a mãe e seus avós maternos, duas (Caio e Paulo) moram com os pais e são vizinhos dos avós maternos, e as outras duas (Edna e Laura) moram com suas mães. Laura convive com o padrasto, depois do falecimento do pai, e Edna vivencia o relacionamento amoroso do pai com a mãe apenas em alguns finais de semana, visto que este mantém outra família. Quatro deles (Caio, Joana, Marcos, Paulo) são filhos únicos. 
Das sete entrevistadas, seis mães relataram que a gravidez não tinha sido planejada. Apenas Lourdes, mãe de Paulo, afirmou que a gravidez foi programada e que havia sofrido alguns abortos espontâneos antes de conseguir finalizar a gestação. Das crianças atendidas, quatro (Edna, Jaime, Joana e Marcos) estavam em seu primeiro tratamento de obesidade. Os demais estavam na seguinte condição: Caio havia feito seu primeiro tratamento aos cinco anos, na própria instituição, mas já o havia interrompido; Paulo já tinha feito um acompanhamento com nutricionista no posto de sua comunidade, e Laura havia começado a fazer acompanhamento aos três anos de idade em sua comunidade, mas, desde o segundo semestre de 2009, havia sido encaminhada à instituição.

Através das informações coletadas, verificou-se que, das crianças que estavam em condição de retorno de consultas anteriores, Marcos, Edna e Jaime não haviam conseguido perder nem manter seu peso, e Paulo e Joana haviam conseguido perder peso, sendo que Paulo necessitou ficar internado durante duas semanas para perda urgente de peso e para normalização da pressão arterial. Já Laura não havia perdido, mas conseguido manter seu peso, e, com o crescimento corpóreo, seu quadro havia melhorado um pouco. Caio estava na sua primeira consulta. É válido salientar que, mesmo com algumas melhoras apresentadas por algumas crianças, nenhuma delas havia conseguido sair do quadro da obesidade.

\section{Dados obtidos na entrevista}

De acordo com os objetivos da pesquisa, foram identificados dois eixos temáticos:

1) elementos presentes na história familiar das crianças com obesidade, subdividido nos subtítulos: contexto do nascimento da criança, relacionamento entre os pais e início da obesidade, 2) sentimentos e dificuldades expressos pela família, com os temas: modificações na rotina do lar decorrentes do tratamento e consequências psíquicas da obesidade.

\section{Elementos presentes na história familiar das crianças com obesidade}

O contexto de nascimento da criança

No período da gestação, os ajustamentos na família são necessários para que a criança seja acolhida e investida de sentimentos. É importante aprender a conhecer e a reconhecer as necessidades desse novo ser. Ao falar sobre os acontecimentos importantes ocorridos durante a gestação, seis das sete entrevistadas relataram que a gravidez não tinha sido planejada e que muitas mudanças aconteceram em suas vidas devido a esse acontecimento.

\footnotetext{
Eu não queria ter engravidado, porque na época eu só namorava o pai dele. Minha mãe me colocou para fora de casa e meu esposo assumiu minha gravidez. Ela é muito estressada. Só vamos à casa dela porque ela é minha mãe, mas é muito difícil lidar com ela (Maria, 29 anos, mãe de Caio, nove anos).
}

No relato de Maria, percebe-se o seu distanciamento afetivo da mãe, especialmente no momento da gravidez, e que se estende ao longo do desenvolvimento de Caio. Isso contraria a necessidade que a mulher grávida tem de sentir que foi amada e cuidada pela mãe, para que possa também amar e cuidar do seu bebê (Missonnier, 2004). Acredita-se que a experiência e a percepção da família de origem dos pais exercem um grande impacto sobre a forma como a pessoa interage no seu próprio sistema familiar. Postula-se que a falha na estruturação da relação de Maria com a mãe pode ter acarretado a dificuldade que ela tem para reconhecer as necessidades de Caio, fora da esfera alimentar. Assim, o alimento oferecido indiscriminadamente 
a ele pode ser uma forma de manifestar cuidados e amor.

Além disso, para Spada (2005) e Pisciolaro e Azevedo (2010), as famílias com histórico de abuso de álcool, drogas ou doenças afetivas são suscetíveis de possibilitar que seus integrantes desenvolvam algum tipo de doença alimentar como consequência do preenchimento de um vazio emocional. O relato abaixo apresenta o ambiente doméstico vivido por essa criança.

Lá em casa é um descontrole total. Meu marido é alcoólatra, bebe em todo o canto, fala alto, grita, diz muito palavrão e fica nu. Ela presencia tudo, e, para completar, ele implica muito com Joana, briga e coloca a culpa sempre nela. É mais uma pessoa colocando a culpa nela. Ele é um homem doente, e por isso é um aperreio total (Jacira, 59 anos, avó de Joana, nove anos).

\section{Relacionamento entre os pais}

Menendez et al. (2004) acreditam que os filhos deveriam ser resultado da proximidade e do projeto da vida em comum do casal. Wagner e Mosmann (2009) afirmam que a forma como se estabelecem as relações conjugais resultará em consequências que transbordam e atingem a relação pais-filhos. Assim, quando não ocorre uma integração funcional entre o casal e constata-se a lacuna da função parental, a situação poderá repercutir negativamente no desenvolvimento da criança, predispondo-a ao surgimento de doenças alimentares (Bayer et al. 2010; Spada, 2005).

Quando disse ao meu marido que estava grávida, foi um choque para ele. A família dele me culpou pela gravidez, porque não vivíamos bem, e disse que eu tinha feito para segurar o casamento. Depois que Marcos nasceu, nos separamos e os conflitos continuaram por diversos motivos, entre eles, a agressividade com que ele trata o menino (Marta, 33 anos, mãe de Marcos, oito anos).
Observa-se, no relato de Marta, uma dificuldade na função de casal que se estende à função paterna. Ela descreve falhas do genitor na realização dos seus papéis, tanto como companheiro quanto como pai. A tensão gerada nessa situação interfere na estabilidade do sistema familiar. A colocação de Jacira, abaixo, avó de Joana, demonstra a indiferença do pai desta com a filha, no momento em que ela revelou a gravidez.

\begin{abstract}
Minha filha estava namorando quando engravidou de Joana. Ela tinha 20 anos. O pai de Joana desapareceu quando soube da gravidez (Jacira, 59 anos, avó de Joana, nove anos).
\end{abstract}

Esses relatos corroboram o pensamento de Houzel (2004) ao considerar que, para alguns casais, a ideia de ter um(a) filho(a) pode ser uma decisão importante, enquanto, para outros, poderá trazer dificuldades no desenvolvimento da identidade familiar e sentimentos ambíguos com relação à maternidade e/ou paternidade.

\section{Início da obesidade}

Apesar de acreditar que o modelo da família tradicional, em que o pai era o provedor e a mãe se ocupava da casa e dos filhos, também produzia sintomas psíquicos nas crianças, Roz (2007) afirma que ainda se cultiva uma dívida em relação a essa formação familiar, e são as mulheres as que mais sofrem. Segundo a autora, os conflitos entre o cuidado com os filhos e o trabalho são mais presentes nas mulheres, e geram sentimentos de culpa pelo abandono dos filhos e atitudes compensatórias em relação a eles. Essa dívida faz com que mães e pais se sintam sempre insuficientes, desamparados e culpados em relação aos filhos, e isso se agrava quando estes desenvolvem algum problema que coloca em questão os cuidados referentes a eles. 
Tanto eu como meu esposo trabalhamos fora de casa. Como moro vizinho à minha mãe, peço para ela dar uma olhadinha nele vez por outra. Ele estuda pela manhã, quando chega, almoça, faz a lição e vai assistir televisão. Ele já nasceu gordinho, todo bonitinho e bem saudável (Lourdes, 40 anos, mãe de Paulo, nove anos).

Nesse relato, vê-se que a saída da mulher para o mercado de trabalho é marcada não somente pela mudança de status (sair do âmbito privado para o público, desenvolver uma carreira) mas, nesse caso, por uma necessidade de complementação da renda familiar. Outra questão que se observa no caso da família de Paulo é a identificação entre obesidade e saúde. Algumas famílias se apoiam no simbolismo saúde-gordura, o que dificulta o emagrecimento da criança por acreditarem que criança sadia é a que nasce gordinha e bonita (Osório, 2004). Assim, pode acorrer uma dificuldade por parte dos familiares em perceber a obesidade na criança.

\section{2- Sentimentos e dificuldades expressos pela família}

Modificações na rotina do lar em decorrência do tratamento

Algumas entrevistadas expressaram suas dificuldades para mudar a rotina da casa em função do tratamento da criança. Campos (2004) cita a cultura alimentar de algumas famílias, que gravita em torno do alimento, o que favorece a preservação da doença alimentar através de hábitos inadequados, horários sem nenhum controle e supervalorização do alimento como o único prazer.

Depois que me separei, voltei para a casa do meu pai. Lá não temos privacidade, o ambiente é muito agitado, porque tem meus irmãos também. Jaime gosta de imitar as coisas que meu irmão faz, como comer vendo televisão e dormir tarde; quando digo que não, esse meu irmão reclama comigo. Sinto dificuldades em seguir o controle da nutricionista, porque, quando proíbo um alimento, vem outro e dá para ele. Nos finais de semana, quando não saímos para comer uma pizza, peço para ele comprar um bolo de ovos, cachorroquente ou coxinha, Jaime me cobra muito para fazer essas coisas (Adriana, 33 anos, mãe de Jaime, nove anos).

O que se nota no relato de Adriana é a falta de apoio familiar, além de uma dinâmica familiar conflituosa, desorganizada e pouco coesa, que facilita os hábitos inadequados. Também se percebe a interferência e a aliança do tio com a criança, o que dificulta as regras familiares, bem como a dificuldade da mãe para se contrapor aos desejos alimentares inadequados de Jaime.

\section{Consequências psíquicas da obesidade}

Para Lemes (2004) o aspecto emocional está sempre associado à obesidade, como causa ou consequência dela, até mesmo por se tratar de uma doença não aceita socialmente. Spada (2005) acrescenta que a dimensão psíquica pode influenciar negativamente na capacidade da criança de distinguir entre a fome fisiológica e aquela que alivia algum tipo de desconforto emocional, o que faz com que ela coma sem perceber o próprio limiar de saciedade.

A alimentação é um pouco desregrada, porque, toda vez que ele tem fome, come aquele pratão de almoço, e ele tem fome toda hora. Paulo almoça, e, duas horas depois, quer comer novamente, a mesma coisa e com igual quantidade do almoço, de preferência que seja macarrão com alguma fritura. Saio para trabalhar e, quando chego, tenho que ficar vasculhando para ver se ele comeu mais do que o determinado (Lourdes, 40 anos, mãe de Paulo, nove anos).

Laura é muito ansiosa, rói unha e fica com raiva quando a irmã fala que ela está muito gorda, briga e esperneia. Em casa, ela briga 
com todos. Fico no pé dela para que ela perca peso. Muitas vezes ela acorda de madrugada e pede para comer um prato de arroz, coloco, mas reclamo e paro de falar porque percebo que ela fica mais ansiosa e triste (Lúcia, 32 anos, mãe de Laura, oito anos).

Percebe-se, no que dizem as entrevistadas, a existência de algumas repercussões como: ansiedade, tristeza, irritabilidade e agressividade no cotidiano das crianças, o que corrobora a literatura referente à obesidade na infância (Cataneo et al., 2005; Luiz et al., 2005, 2010). Nessa circunstância, a consequência pode estar relacionada aos episódios de comer compulsivamente, descritos pelas mães de Paulo e Laura, que ingerem grandes quantidades de alimentos sem estarem famintos.

Nota-se que as famílias apresentam dificuldades para gerenciar essa questão, pressionadas, por um lado, pela necessidade de a criança perder peso e, por outro, pela sensação de deixarem a criança insatisfeita e, assim, aumentarem seus sentimentos negativos.

\section{Expectativas frente ao tratamento e atitudes tomadas para enfrentar o problema}

O Departamento de Nutrição do ambulatório onde foi feita esta pesquisa presta assistência nutricional individualizada aos pacientes da instituição, promovendo orientação acerca das diversas patologias. A avaliação nutricional é realizada através de uma anamnese alimentar que tem como objetivos o diagnóstico, a reeducação alimentar e o monitoramento da evolução do tratamento. Os trechos a seguir exemplificam o que as mães esperam do tratamento:

Ela tem nove anos, sabe comer com as mãos, sabe pegar as coisas, eu converso, ela não obedece, eu acabo batendo nela. Às vezes penso que não adianta, que ela não tem jeito (Marcela, 32 anos, mãe de Edna, nove anos).

Laura não aceita as colocações com facilidade, explico o que tem que ser feito e parece que ela não quer entender, ou o problema já está em mim, que pareço ver coisas demais. Estou buscando esse tratamento para ajudá-la (Lúcia, 32 anos, mãe de Laura, oito anos).

Espero que Paulo consiga baixar o peso. Para ajudá-lo, o pai comprou um jogo e eu prometi comprar os cartuchos, caso ele perdesse peso (Lourdes, 40 anos, mãe de Paulo, nove anos).

As entrevistadas relataram que esperam do tratamento a perda de peso das crianças. No entanto, mantêm uma postura adversa ao processo de reeducação alimentar, delegando a responsabilidade para a criança, punindo-a quando ela não obedece ao combinado, seja com agressão física, como se vê no caso de Edna, seja recorrendo à barganha, conforme se observa no relato de Lurdes, mãe de Paulo. Dessa maneira, na tentativa de proporcionar a perda de peso da criança, as interações na família podem funcionar como controle dos relacionamentos (Coppins et al., 2011).

A entrevistada Lúcia relatou que buscou o tratamento para ajudar Laura, em virtude de suas dificuldades de entendimento com a filha. Aun, Vasconcellos e Coelho (2005), bem como Osorio (2004), ressaltam que a obesidade na infância pode servir como uma luta de poder que se mostra através de birras e de implicâncias da criança com um dos pais, na tentativa de resistir efetivamente às investidas do tratamento e de obter ganhos secundários à obesidade.

Quanto às atitudes tomadas para enfrentar a obesidade, a maioria informou atender às solicitações recomendadas pelas nutricionistas, que se referem às modificações nos hábitos alimentares. Edwards et al. (2006) ressaltam a importância do aconselhamento psicológico e 
nutricional aos familiares sobre as mudanças de estilo de vida, no intuito de modificar o ambiente familiar e de melhorar as estratégias de adesão ao tratamento.

\section{Considerações finais}

A obesidade é uma condição complexa que afeta não somente países desenvolvidos mas também se estende, cada vez mais, aos países em desenvolvimento, cujo foco, anteriormente, estava voltado para a desnutrição. Sua prevalência reflete as profundas modificações que a sociedade vem passando ao longo dos anos: saída da mulher para o mercado de trabalho, proliferação das redes de fast-food e mudanças das brincadeiras infantis que faziam despender energia (exemplo: pula-corda) para o uso de games em computadores, e, por isso, a obesidade infantil tornou-se um sério desafio à saúde pública no século XXI.

Os resultados obtidos evidenciaram a existência de conflitos precoces nos relacionamentos entre pais e filhos. Por sua vez, o próprio relacionamento entre os pais, na sua maioria, mostrou-se bastante tumultuado, o que faz pensar que a obesidade na criança venha a ser uma forma de mascarar tais dificuldades ao focalizarem-se na doença do(a) filho(a). Retomando os objetivos específicos, no que se refere aos sentimentos expressos pelas famílias, constatou-se a existência de repercussões psíquicas do excesso de peso nas crianças, que acabam sendo alvo de chacotas, e, em decorrência disso, apresentam sentimentos de ansiedade, tristeza e irritabilidade bem como o comportamento de comer compulsivamente. Observaram-se dificuldades geradas no contexto familiar pela modificação da rotina alimentar da família em função do tratamento, os impasses que elas enfrentam para compreender a necessidade de impor limites à criança e para solicitar a contribuição de todos a fim de superar o problema.

Os depoimentos dos familiares quanto às expectativas frente ao tratamento evidenciaram que alguns estavam esperançosos com os possíveis resultados, enquanto outros apresentaram incredulidade decorrente dos fracassos de tentativas anteriores. Também se pode perceber dificuldades, por parte dos familiares, em adequar o ambiente da criança às intervenções solicitadas pelos profissionais. As estratégias utilizadas para enfrentar o problema variaram entre o encaminhamento para a instituição, a barganha com a criança para obterem a aderência ao tratamento e a tentativa de melhorar o cardápio da casa.

No que se refere aos fatores que predispõem e mantêm a obesidade na infância, constatouse que, no sistema familiar das crianças estudadas, uns são retroalimentadores das atitudes dos outros, e essas influências acabam sendo recíprocas e inevitáveis. É o que apregoa a propriedade da retroalimentação presente na teoria dos sistemas. Dessa forma, não é fácil isolar o que sejam causas e efeitos das ações de cada um, que se refletem no comportamento alimentar da criança. No entanto, acredita-se que a não aceitação da gravidez, por parte de um dos pais, a desarmonia existente nas relações familiares, as dificuldades para implementar modificações na rotina familiar em função do tratamento, bem como as expectativas que a família possui frente ao problema regulam o funcionamento do sistema familiar, predispondo e mantendo a obesidade das crianças. Isso remete à importância do esclarecimento e do acompanhamento psicológico às famílias quanto à sua responsabilidade no processo de tratamento das crianças acometidas pela obesidade.

Sendo esta uma pesquisa de natureza qualitativa, sabe-se não ser possível 
generalizar os resultados. Sugere-se a realização de novas investigações que possam acrescentar ou aprofundar outras questões que fugiram ao escopo deste trabalho. Uma possibilidade seria diversificar a faixa etária e a classe social dos participantes. Também se propõe a participação das crianças, em uma tentativa de compreender suas dificuldades, comportamentos e sentimentos frente à própria obesidade.
Espera-se que as informações contidas neste estudo possam, de alguma maneira, subsidiar o trabalho dos profissionais que lidam com essa temática, ao proporcionar conhecimento acerca do funcionamento familiar das crianças acometidas pela obesidade. Certamente, ainda há muito a ser debatido e investigado sobre o referido fenômeno.

\section{Priscilla Machado Moraes}

Mestre em Psicologia Clínica pela Universidade Católica de Pernambuco e doutoranda do programa de pósgraduação em Psicologia Clínica da Universidade Católica de Pernambuco, Recife - PE - Brasil.

Email: pris25@globo.com

\section{Cristina Maria de Souza Brito Dias}

Doutora em Psicologia pela Universidade de Brasília, professora e pesquisadora do programa de pós-graduação em Psicologia Clínica da Universidade Católica de Pernambuco, Recife - PE - Brasil.

E-mail: cristina_britodias@yahoo.com.br

Endereço para envio de correspondência:

Avenida Boa Viagem, 6836, Bloco 13, Ap. 12., Boa Viagem. CEP: 51130-000. Recife, PE

Recebido 04/04/2012, 1a Reformulação 20/06/2012, Aprovado 15/10/2012.

Andrade, L. H. S. G., \& Gorenstein, C. (1998). Aspectos gerais das escalas de avaliação e ansiedade. Revista de Psiquiatria Clínica, 25(6), 258-290.

Aun, J. G., Vasconcellos, M. J. E., \& Coelho, S. V. (2005). Atendimento sistêmico de famílias e redes sociais: fundamentos teóricos e epistemológicos. Belo Horizonte: Ophicina de Arte \& Prosa.

Bastos, B. S. M. P. (2005). A auto-estima da criança que sofre violência física pela família. Dissertação de mestrado. Universidade Federal do Rio Grande do Norte, Natal, RN.

Baptista, M. N., Vargas, J. F., \& Baptista, A. S. D. (2008). Depressão e qualidade de vida em uma amostra brasileira de obesos mórbidos. Avaliação Psicológica, 7(2). Recuperado em jun., 2010, de http://pepsic.bvsalud.org/scielo.php?script=sci_ arttext\&pid=S1677-04712008000200014\&lng=pt\&nrm=iso\&tl ng=pt Brasil. (1996). Ministério da Saúde: Diretrizes e normas regulamentadoras de pesquisas envolvendo seres humanos. Resolução no 196. Brasília, DF: Conselho Nacional de Saúde.
Bruch, H. (1977). A importância do excesso de peso. In P. J. Collip (Org.), Tratamento da criança obesa (pp. 83-90, U. C. Arantes, trad.). São Paulo: Manole.

Bayer, A. A. A., Vasco, C. C., Lopes, S. R. A., \& Teixeira, C. J. C. (2010). Intervenção grupal em pacientes com obesidade e seus familiares: relato de experiência. Psicologia: Ciência e Profissão, 30(4). Recuperado em 27 ago., 2011 de http:// pepsic.bvsalud.org/scielo.php?script=sci_arttext\&pid=\$141498 932010000400015\&lng=pt\&nrm=iso

Campos, A. L. R. (2004). Aspectos psicológicos da obesidade. In M. Fisberg (Coord.), Atualização em obesidade na infância e adolescência (pp. 97- 102). São Paulo: Atheneu.

Cataneo, C., Carvalho, A. M. P., \& Galindo, E. M. C. (2005). Obesidade e aspectos psicológicos: maturidade emocional, autoconceito, locus de controle e ansiedade (versão eletrônica), Psicologia: Reflexão e Crítica, 18(1), 1-12.

Costa, F. S., Bandeira, D. R., Trentini, C., Brilmann, M., Friedman, R., \& Nunes, M. A. (2009). Considerações acerca 
da avaliação psicológica das comorbidades psiquiátricas em obesos. Psicologia em Estudo, 14(2). Recuperado em 16 set., 2011, de http://www.scielo.br/scielo.php?pid=S141373722009000200009\&script=sci_arttext

Coppins, D. F., Margetts, B. M., Fa, J. L., Brown, M., Garret, F., \& Huelin, S. (2011). Effectiveness of a multi-disciplinary familybased programme for treating childhood obesity. European Journal of Clinical Nutrition, 65, 903-909.

Dias, C. M. S. B., Aguiar, A. G. S., \& Hora, F. F. A. (2009). Netos criados por avós: motivos e repercussões. In T. F. Carneiro. Casal e família: permanências e rupturas (pp. 41-58). São Paulo: Casa do Psicólogo.

Edwards, C., Nicholls, D., Croker, H., Van Zyl, S., Viner, R., \& Wardle, J. (2006). Family-based behavioural treatment of obesity: Acceptability and effectiveness in the UK. European Journal of Clinical Nutrition, 60, 587-592.

Fisberg, M. (2004). Primeiras palavras: uma introdução ao problema de peso excessivo. In M. Fisberg (Org.), Atualização em obesidade na infância e adolescência (pp. 01-09). São Paulo: Editora Atheneu.

Houzel, D. (2004). As implicações da parentalidade. In L. SolisPonton (Org.). Ser pai, ser mãe parentalidade: um desafio para o terceiro milênio (pp. 47-51, M. C. P. Silva, trad.). São Paulo: Casa do Psicólogo.

Instituto Brasileiro de Geografia e Estatística (IBCE). (2010). POF 2008-2009 - Desnutrição cai e peso de crianças brasileiras ultrapassa padrão internacional. Recuperado em 22 out., 2011, de http://www.ibge.gov.br/home/presidencia/noticias/ noticia_visualiza.php?id_noticia $=1699$ \&id_pagina $=1$

Lemes, S. O. (2004). Acompanhamento da obesidade na infância e adolescência. In M. Fisberg (Coord.), Atualização em obesidade na infância e adolescência (pp. 85-96). São Paulo: Atheneu.

Luiz, G. A. M. A., Gorayeb, R., Liberatore, Júnior, R. D. R., \& Domingos, N. A. M. (2005). Depressão, ansiedade e competência social em crianças obesas (online). Estudos de Psicologia, 10(1), 35-39. Recuperado em 15 abr., 2009, de http:// www.scielo.br/pdf/epsic/v10n1/28006.pdf

Luiz, G. A. M. A., Gorayeb, R., \& Liberatore, Júnior, R. D. R. (2010). Avaliação de depressão, problemas de comportamento e competência social em crianças obesas. Estudos de Psicologia, 27(1). Recuperado em 14 fev., 2011, de http:// www.scielo.br/scielo.php?script=sci_arttext\&pid=S0103166X2 010000100005\&lng=pt\&nrm=iso

Menendez, J. A. B., Lebovici, S., Salinas, J. L., Movo, M. R., Solis, L., Botbol, M., Durán, M. M., \& Córdova, A. (2004). A função do pai: na consulta terapêutica pais-bebês e no tratamento do transtorno alimentar na criança. In L. Solis-Ponton (Org.), Ser pai, ser mãe parentalidade: um desafio para o terceiro milênio (pp. 57-65, M. C. P. Silva, trad.). São Paulo: Casa do Psicólogo.

Minayo, M. C. (2007). O desafio do conhecimento: pesquisa qualitativa em saúde. São Paulo: Hucitec.

Mishima, F. K. T., \& Barbieri, V. (2009). O brincar criativo e a obesidade infantil. Estudos de Psicologia, 14(3). Recuperado em 25 abr., 2011, de http://www.scielo.br/pdf/epsic/v14n3/ a09v14n3.pdf
Missonnier, S. (2004). O início da parentalidade, tornar-se mãe, tornar-se pai. As interações dos pais e da criança antes do nascimento. In L. Solis-Ponton (Org.), Ser pai, ser mãe parentalidade: um desafio para o terceiro milênio (pp. 115-122, M. C. P. Silva, trad.). São Paulo: Casa do Psicólogo.

Murdoch, M., Payne, N., Samani-Radia, D., Rosen-Webb, J., Walker, L., Howe, W., \& Lewis, P. (2011). Family-based behavioural management of childhood obesity: Service evaluation of a group programme run in a community setting in the United Kingdom. European Journal of Clinical Nutrition, $65,764-767$.

Organização Mundial de Saúde. (2006). Obesidade e sobrepeso. Recuperado em 31 ago., 2010, de http://www.who.int/ mediacentre/factsheets/fs311/en/index.html

Osorio, L. C. (2004). A família como sistema. In M. J. Filho \& M. Burd (Orgs.). Doença e família (pp. 29-42). São Paulo: Casa do Psicólogo.

Pereira, C., \& Chehter, E. Z. (2011). Impulsividade na obesidade: questões conceituais e metodológicas. Arquivos Brasileiros de Psicologia, 63(1). Recuperado em 22 nov., 2011, de http:// seer.psicologia.ufrj.br/index.php/abp/article/view/692/492

Pisciolaro, F., \& Azevedo, A. P. (2010). Transtorno de compulsão alimentar periódica. In T. A. Cordás \& A. T. Kachani (Orgs.), Nutrição em psiquiatria (pp. 167-180). Porto Alegre: Artmed.

Roz, D. F. P. (2007). Família do obeso. In N. Setian (Coord.), Obesidade na criança e no adolescente: buscando caminhos desde o nascimento (pp. 181-189). São Paulo: Rocca.

Setian, N. (2007). Obesidade na criança e no adolescente: buscando caminhos desde o nascimento. In N. Setian (Coord.), Obesidade na criança e no adolescente: buscando caminhos desde o nascimento (pp. 01-05). São Paulo: Rocca.

Simon, V. G. N., Souza, J. M. P., Leone, C., \& Buongermino de Souza, S. (2009). Prevalência de sobrepeso e obesidade em crianças de dois a seis anos matriculadas em escolas particulares no município de São Paulo. Revista Brasileira de Crescimento e Desenvolvimento Humano, 19 (2). Recuperado em 25 jan., 2011, de http://pepsic.bvsalud.org/scielo.php?script=sci_artte xt\&pid=S0104-12822009000200002

Spada, P. (2005). Obesidade infantil: aspectos emocionais e vínculo mãe/filho. Rio de Janeiro: Revinter.

Wagner, A., \& Mosmann, C. (2009). A promoção da qualidade conjugal como uma estratégia de proteção dos filhos. In C. T. Féres (Org.). Casal e família: permanências e rupturas (pp. 169- 180). São Paulo: Casa do Psicólogo. 